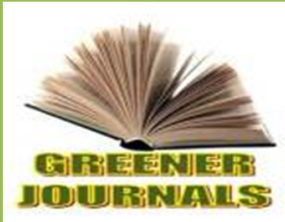

\title{
Youth in Agriculture; Perceptions and Challenges for Enhanced Participation in Kajiado North Sub-County, Kenya
}

\section{Lucy Karega Njeru (PhD)}

\author{
Department of Agricultural Economics and Extension, University of Embu P. O. BOX 6-60100 \\ Embu, Kenya.
}

Article No.: 100117141

DOI: 10.15580/GJAS.2017.8.100117141

Submitted: 01/10/2017

Accepted: 07/10/2017

Published: 14/10/2017

*Corresponding Author

Lucy Karega Njeru

E-mail: lucykarega@gmail.com;

karega.lucy@embuni.ac.ke

Keywords:

Agriculture, Employment, perceptions, challenges, Youth
Agriculture in Kenya can develop gainful employment opportunities for youth that would enable them exploit their economic innovation and enhance equal opportunities for the male and female youth for national economic growth. Improving youth participation in the agricultural sector is thus of paramount importance for the nation to develop. Youth's interest in agriculture is however likely to be positively related to their perceptions in terms of agricultural-related activities mostly being portrayed as difficult and assumed to be meant for the ageing rural population. The relationship between youth's perception on agriculture and their participation in agriculture in Kajiado North Sub-County was poorly understood and hence the need for this study, which used a crosssectional design to collect data from 397 randomly, selected youth and 22 youth and agricultural officers. Content validity of the youth and agricultural officers' questionnaires was ascertained by extension experts while reliability was determined through a pilot test involving 30 respondents. The reliability coefficient were $0.86 \alpha$ and $0.80 \alpha$ respectively, which were above the 0.70 threshold for acceptable reliability. The study showed that there is a statistically significant relationship between youth perception on agriculture and their participation in the study area $(r=0.675 p=0.01), p=.001)$. The study revealed youth's negative perceptions of agriculture as a reason why many did not participate in the sector; where $18.1 \%$ youth felt that there were no role models in agriculture and $17.6 \%$ claimed that agriculture was not profitable. The government and other development partners should come up with strategies of addressing the issue of negative perception that has an implication on youth participation in agriculture. Government can ensure that agricultural education and training reflects the needs of the agricultural labour market and enhance youth's familiarity with the world of work, including its practical challenges and rewards. Youth should be directly linked to business partners and they should be given hands-on experience. 


\section{INTRODUCTION}

Agriculture contributes about $30 \%$ of Kenya's total Gross Domestic Product (GDP), accounts for $65 \%$ of national export earnings and caters for over $80 \%$ of employment opportunities. It provides a livelihood to about $80 \%$ of the population (Central Intelligence Agency (CIA) World Facts, 2014). Rural households rely on agriculture for most of their income mainly from smallholder farming, which produces the majority of Kenya's agricultural output.

Kenya government revised the Strategy for Revitalizing Agriculture (SRA), which was adopted in 2008 to create an improved agricultural legislation (GoK, 2013; Kangai, Mburu \& Nyikal, 2011). In 2010 the SRA, originally intended to run from 2004-2014, was superseded by the Agricultural Sector Development Strategy 2010-2020 (ASDS) that foresees a food secure and prosperous nation by 2020 and aims to achieve a paradigm shift from subsistence to commercial agriculture.

Emphasizing agricultural growth, smallholder productivity as well as employment creation however in bid to reducing the cycle of poverty raises a concern, especially given the ageing farmer population. The concern should address issues on whether Kenyan youth adequately participate in agriculture, the influence their perceptions on agriculture and their involvement in the sector could have and high rate of unemployment in Kenya. A report by Uganda National Bureau of Statistics (UNBS) (2012) revealed that formal jobs are viewed as a solution to youth unemployment, although prospects of finding these kind of jobs is limited, as the number of youth entering the labour force far outweighs the number of jobs available in the formal wage sector. Agriculture is thus likely to continue being a source of employment and livelihood especially for countries that heavily depend on it. However, Brooks, Zorya and Gautam (2012) reported that agriculture is not perceived as a viable source of employment as it remain highly unattractive to the youth. Studies by Bezu and Holden (2014) and Noorani (2015) indicated that Ethiopia has not attracted young people to agriculture despite the country's serious food insecurity.

Available literature (FAO, 2014; ILO, 2013) in SSA suggests an ageing farming population with a mean of 55 years and high unemployment rate of youth of $75 \%$. Youth unemployment rate in SSA is related to higher levels of poverty. It is estimated that $20.1 \%$ of youth in SSA who are employed earn only USD 1.25 or less per day. This level is referred to as the 'working poverty rate implying that most young people in SSA work by necessity rather than by choice. This situation can be changed by encouraging youth participation in agriculture (AGRA, 2015; ILO, 2013; OECD, 2012).

Youth with dynamism and flexibility have the potential as agents of positive change and this should be ensured by enhancing their participation in agricultural development programs. In the most adverse and risky situations, youth have an extraordinary resilience and ability to cope (AGRA, 2015). Youth are the driving force behind economic prosperity in future decades, only if policies and programs are in place to enhance their opportunities (Brooks, Amy, Goyal, \& Zorya, 2013). However, their interest in farming is likely to be positively influenced by their perceptions on agricultures among other challenges faced.

A key impediment to the involvement of youth in agriculture has been the lack of national efforts to make agriculture attractive to them (World Bank, 2014). Lack of respect towards farmers and lack of role models among young farmers appear as likely reasons for youth not engaging in agriculture. A study by the World Bank (2011) indicated that girls in India are not interested in marrying farmers which stimulates young men to move away from farming and Asian media play a role in demonizing agriculture and rural areas. Media promotes a western and urban lifestyle and thus negatively shapes rural youth's aspirations related to agriculture (Noorani, 2015).

Uganda's agriculture is unattractive to the youth partly because it has been used in schools in the administration of punishments to errant and indisciplined children (Agena, 2011). Those under detention in prisons have many times been hired to work on farms with the head of prisoners cruelly whipping the lazy and weak to match the pace of those who are energetic working ahead of them (Brooks et al., 2012). These cases portray agricultural-related activities as deserving for wrongdoers hence limiting the youth enthusiasm to pursue livelihoods in agriculture. Consequently, possibilities for agriculture-led growth are jeopardized and it is left in the hands of the ageing rural population (Proctor \& Lucchesi, 2012).

African Children from rural areas have less access to education than their urban peers. Apart from lack of educational infrastructure in rural areas, finding good and motivated teachers in rural areas may be a big challenge especially in developing countries (UNICEF, 2013). Moving children up from primary to secondary school is not self-evident in many of these countries. In India for instance, some parents are hesitant in investing in secondary education for their daughters as they rather invest in their dowry (UNESCO, 2012). Not only do rural youth have less access to education, but the education in rural areas is often of less quality and not relevant to rural lives (UNICEF, 2013). African agricultural curricula have disappeared in schools while in Asia it is outdated and inadequate. Therefore, there is a need to include agriculture in the school curriculum from primary school level and that teachers need to instill a positive perception towards agriculture by explaining to their students the many aspects of agriculture; its importance to everyday life; and its career opportunities (Njeru, Gichimu, Lopokoiyit \& Mwangi, 2015).

In most parts of the world, agriculture is seen as a less worthwhile subject, last resort for under-achievers and a dirty job for urban students, hence influencing 
rural youth aspirations in a negative way (Brooks et al., 2012). Training programs for vocational courses in subSaharan Africa and the Arab states mostly reach young men and do not cater to the needs of young women largely due to restricted mobility, young motherhood and limited schooling levels (UNESCO, 2012). Higher education is equally essential for the development of agriculture, thus, creation of high quality universities that focus on agricultural research and establishing linkages with the farming community is very pertinent (Paisley, 2012). United Nations Development Program (UNDP) (2013) confirmed that universities need to be connected with farming communities in order to broaden knowledge, increase research and enhance local problem-solving skills. Unfortunately, in most developing countries, such systems are rarely instituted and access to tertiary agricultural education is low (FAO, 2013; World Bank, 2014).

It is against this back ground that that study determined youth in agriculture, perceptions and challenges in enhanced participation in Kajiado North Sub-County, Kenya.

\section{Statement of the Problem}

Youth in Kenya constitute of about $45 \%$ of the total labour force. Some of these youth work mainly in agriculture, which supports over $75 \%$ of the population and contributes $30 \%$ to the GDP. Young people were estimated to comprise $80 \%$ of the Kenyan population by 2016. This tremendous youth population increase, rising unemployment and therefore high dependence ratio poses a great danger to Kenya's economy. Despite Government's efforts to make agriculture more attractive and profitable to the youth, their participation in the sector is declining as they increasingly migrate to cities in search of remunerative and decent employment. Furthermore, although the youth hold Kenya's future due to their enormous energy and aspirations, most of them in the study area considered agriculture to be less attractive compared to other professions. Reducing youth unemployment through participation in agriculture is a challenge in Kenya since the average age of a farmer is about 60 years and at this age bracket, farmers are less venturous, averse to risks and hesitant to adapt innovations making it difficult to transform agriculture from subsistence to income generating activities. Although youth engagement in agriculture could greatly reduce youth unemployment in the country, $70 \%$ youth in the study area were unemployed. Youth perception towards agriculture is a factor that influence their participation in agriculture in Kenya. This is a challenge in Kajiado North Sub-County since its influence on youth involvement in agricultural activities and development were poorly understood and documented. This therefore made it difficult for Kenyan leaders and their development partners to formulate innovative strategies for enhancing youth's positive perception on agriculture. This study has provided information that the Government and other leaders can use to make informed decision on how to improve youth's positive perceptions towards agriculture thereby enhancing their participation in the sector.

\section{Purpose and Objective of the Study}

The study sought to determine youth in agriculture, perceptions and challenges in enhanced participation in Kajiado North Sub-County. The researchers assumed that there was a statistically significant relationship between youth perceptions towards agriculture and their participation in agriculture in Kajiado North Sub-County.

\section{RESEARCH METHODOLOGY}

A cross-sectional design was used to collect data from 397 randomly selected youth and 22 youth and agricultural officers. This design provides self-reported facts about respondents, their feelings, attitudes, opinions and habits and is excellent for collecting original data (Kombo \& Tromp, 2007; Kothari, 2008). It enables the researcher to study a large population with only a portion of it being used to provide the required data (Kothari, 2008).

\section{Instrumentation and Data Collection Procedures}

A self-administered questionnaire with information on the influence of the differences between male and female youth in their level of participation in agriculture, developed by the researcher with open and closedended items, was used for the youth and agricultural extension officers. The questionnaires' content validity was ascertained by five extension experts while a pilot test involving 30 youth was conducted to determine its reliability, which was $0.83 \alpha$. This was above the 0.70 minimum acceptable for educational research at a significance level of 0.05 set as priori.

\section{Data Analysis}

Data analysis involved qualitative and quantitative methods. In the qualitative data analysis, emerging trends were categorized based on research objectives. The data on gender difference was summarized into categories (males and females) and analyzed using a ttest at $0.001 \alpha$ significance level. It found out if the mean difference between the level of participation in agriculture between the male and female youth was significant. Frequency tables and percentages were used to summarize and present quantitative data.

\section{RESULTS}

A respondent's age was important in determining the average age of youth involved in agricultural production 
in the Sub-County. Most of the youth $(63.4 \%)$ were 26 35 years while the rest $(36.6 \%)$ were $18-25$ years implying that agriculture in the Sub-County had attracted very few young people between 18 and 20 years. In terms of formal education, $60.2 \%$ had secondary (Form 4) to college (certificate or diploma) education. Of the remaining $39.8 \%, 7.3 \%$ had no formal education, $20.4 \%$ had primary education (standard 1-8) and only $12.1 \%$ had university education.

Youth Perceptions towards Agriculture

Table 1: Reasons why Many Youth did not participate in Agriculture

\begin{tabular}{lrr}
\hline Challenges & Frequency & Percentage \\
No role models in agriculture & 72 & 18.1 \\
Agriculture is not profitable & 70 & 17.6 \\
Lack of access to viable markets & 63 & 15.8 \\
Lack of access to enough land & 60 & 15.1 \\
Lack of enough finances & 50 & 12.7 \\
Agriculture is a low status career & 42 & 10.6 \\
Agriculture to be practiced by the old and illiterate & 40 & 10.1 \\
\hline Total & $\mathbf{3 9 7}$ & $\mathbf{1 0 0 . 0}$ \\
\hline
\end{tabular}

Table 1 indicates that $18.1 \%$ youth felt that there were no role models in agriculture. This was followed by $17.6 \%$ who claimed that agriculture was not profitable, while $15.8 \%$ said that it was due to lack of access to good markets. Others $15.1 \%$ claimed that there was inadequate access to land, $12.7 \%$ cited inadequate finances for investing in agriculture, $10.6 \%$ said that agriculture was regarded as a low status career and $10.1 \%$ felt that agriculture should be practiced by the old and illiterate members of society. Over half, $56.4 \%$ of the youth revealed negative perceptions of agriculture as a reason why many did not participate in the sector. Hence, agrees with the findings by Leavy and Hossain (2014) who contends that poor perceptions of agriculture influences youth participation in agriculture. Farming is perceived to be a difficult life that offers no attraction to the youth. It also concurs with Noorani (2015) and Proctor and Lucchesi (2012) who found that agriculture is considered as a high risk venture as it depends on rainfall, has marginal returns and is commonly associated with low incomes, drudgery, low societal standing, all of which fail to meet the aspirations of the youth. Aspirations are not just about economic opportunities, status is important. Agriculture is assumed to be unappealing to young people because it does not bring status regardless of economic outcomes.

\section{Correlation Measure for Youth Perception of Agriculture and their Participation}

During data analysis, youth responses for each item forming the 6 variables on youth perception of agriculture were converted to scores with the most positive response "Strongly Agree" assigned a score of 5 , "Agree" a score of 4, "Neutral" a score of 3, "Disagree" a score of 2 and the most negative response "Strongly Disagree" a score of 1 . A total of the scores for each item were calculated and the mean, standard error (SE), standard deviation (SD) and range were determined as show in Table 2.

Table 2: Descriptive Indicator Statistics for Youth Perceptions of Agriculture $(n=397)$

\begin{tabular}{lrrrr}
\hline Indicators & Mean & SE & SD & Range \\
\hline A promising career & 3.000 & 0.067 & 1.346 & 4 \\
Agriculture is a low status career & 2.226 & 0.062 & 1.236 & 4 \\
Agriculture not profitable & 3.123 & 0.084 & 1.680 & 4 \\
Included in school curriculum & 2.083 & 0.057 & 1.139 & 4 \\
Not to be used a punishment & 2.324 & 0.074 & 1.478 & 4 \\
A career choice & 3.904 & 0.071 & 1.428 & 4 \\
Index of youth perceptions of agriculture & 18.06 & 0.447 & 8.914 & 30 \\
\hline
\end{tabular}


The scores for the six indicator variables created an index of youth perceptions towards agriculture that had a mean of 18.06 and varied between 5 and 30 . The reliability of the index using Cronbach's alpha was found to be 0.861 . The frequency distribution of the index is given in Table 3.

Table 3: Index of Youth Perceptions of Agriculture

\begin{tabular}{lrr}
\hline Index & Frequency & Per cent \\
\hline 5 to 10 & 126 & 31.7 \\
11 to 20 & 70 & 17.6 \\
21 to 30 & 201 & 50.7 \\
\hline Total & 397 & $\mathbf{1 0 0 . 0}$ \\
\hline
\end{tabular}

Hypothesis: - There is no statistically significant relationship between youth perceptions of agriculture and their participation in agriculture in Kajiado North Sub-County. Correlation analysis using the index of youth perceptions towards agriculture and their participation in agriculture was used to test the above hypothesis and the results are given in Table 4 .

Table 4: Correlation for Youth Perceptions and their Participation in Agriculture

\begin{tabular}{lccc}
\hline Variables & $\mathbf{R}$ & $\mathbf{p}$ & $\mathbf{n}$ \\
\hline Youth participation in Agriculture & 0.675 & 0.01 & 397 \\
Youth perception on agriculture & & &
\end{tabular}

Correlation analysis between the youth perceptions of agriculture and youth participation in agriculture show a statistically significant positive relationship ( $r=0.675$, $\mathrm{p}=0.01$ ). We therefore reject the null hypothesis and indicate that there is a statistically significant relationship between youth perceptions of agriculture and their participation in agriculture since it dominantly influenced their participation in agriculture in the study area. This finding agrees with those by Dalla Valle (2012) and Noorani (2015) who revealed that though there is recognition of the potential of agriculture internationally and nationally, there is decline of youth interest and engagement in the sector. The study findings also agree with those of Brooks et al. (2012) who found that if youth's contribution is matched with the right skills and resources, the much needed youth potential in agricultural sector could be realized. But, as Njeru et al. (2015) and Noorani (2015) contends, lack of incentives and drudgery are some of the reasons why youth are disinterested in agriculture and that in most parts of the world, agriculture is seen as a less worthwhile subject or as a last resort for under-achievers.

These study findings are supported by Brooks et al. (2013) and Noorani (2015) that agriculture in Kenya is not the thing to do unless everything else fails and it is not perceived by many as an activity that provides a good standard of living (Leavy \& Hossain, 2014). Evidence in East Africa also shows that the status of agriculture as "a poor man's job" is further reinforced in schools when students are sent to dig the school farm as a form of punishment for a mistake. Instead, salaried employment in the formal sector is promoted and portrayed as a prestigious occupation with high esteem (Njeru et al., 2015).

According to MOA (2013), majority of the youth in the Kajiado North Sub-County lacked sufficient innovations in the sector, leading to reliance on traditional and labour-based production techniques, hence lacked the motivation to embrace farming as noble career. A report by AGRA (2015) expressed the need to address the long held belief that agriculture and rural based activities are for those who cannot make a living anywhere else and that agriculture need to be rebranded as the new unexplored frontier for growth in business opportunities.

\section{CONCLUSIONS}

Youth perception of agriculture influences their participation in agriculture since youth with positive perceptions participated more in agriculture than those 
with negative perceptions. About $18.1 \%$ of the youth felt that there were no good role models in agriculture, $17.6 \%$ felt that agriculture was unprofitable, $10.6 \%$ felt that it was a low status career and $10.1 \%$ felt that it was for old and illiterate members of society.

\section{RECOMMENDATIONS}

\section{Based on the conclusions of the study, the researchers recommend as follows:}

- The government should ensure access to both information and education, and especially the knowledge of agricultural production, processing techniques, access to information about finance, land and markets.

- Access to tertiary education related to agriculture can be enhanced through scholarships, complemented by strengthening the capacities of universities in developing countries, for example, RUFORUM.

- In order to ensure that the competencies of agricultural graduates meet the needs of an evolving agricultural sector, mechanisms can be introduced to facilitate close collaboration between educational institutions and local farming communities.

- Education in rural areas needs to be made more relevant by, for example, including agriculture in primary and secondary school curricula or modernizing the existing agricultural curricula.

- The government and other development partners should showcase the career paths of successful young farmers and agripreneurs as exemplary models to encourage youth to engage in the agricultural sector.

\section{Recommendation for Further Research}

In order to determine whether the situation is different in other areas, other researchers should replicate the study in order to come up with a more comprehensive program for ensuring youth's positive perception on agriculture thereby enhancing their improved participation in the sector in Kenya.

\section{REFERENCES}

Agena, M. (2011). Increasing Rural Agricultural Productivity through Technology: A Story of a Young Modern Fruit Grower in Apac, Northern Uganda in 'CTA ARDYIS Essay Contest', 2011.

AGRA (Alliance for a Green Revolution in Africa). (2015). Alliance for a Green Revolution in Africa. Africa Agriculture Status Report: Youth in Agriculture in Sub-Saharan Africa. Nairobi, Kenya. Issue No. 3.
Bezu, S. \& Holden, S. (2014). Are Rural Youth in Ethiopia Abandoning Agriculture? World Development, 64, 259-272.

Brooks, K. Amy, G. Goyal, A. \& Zorya, S. (2013). Agriculture as a Sector of Opportunity for Young People in Africa (Policy research working papers). Washington, D.C.: The World Bank

CIA (Central Intelligence Agency) World Facts. (2014). Data on Youth Unemployment and Driving Factors in Kenya. Retrieved May 2, 2015 from https://www.cia.gov/library/publications/worldfactbook/../whatsnew.h

Dalla Valle, F. (2012). Exploring Opportunities and Constraints for Young Agro Entrepreneurs in Africa. Conference abridged version. Rome, FAO.

FAO. (2013). Review of Food and Agricultural Policies in the Kenya 2005-2011 (MAFAP Country Report Series). FAO: Rome.

FAO. (2014). Private and Public Partnership Model for Youth Employment in Agriculture. Experiences from Malawi, Tanzania Mainland and Zanzibar archipelago. Rome.

GoK. (2013). Kenya Population and Housing Census. Volume $1 \mathrm{C}$, Kenya National Bureau of Statistics

ILO (2013). Guidance on How to Address Rural Employment and Decent Work Concerns in FAO Country Activities, 2011.

Kangai, E. Mburu, J. \& Nyikal, R. (2011). Incentives and Constraints of Financing Mechanisms for Compliance to Global GAP Standards among Smallholder Horticultural Farmers in Kenya: University of Nairobi. 26th - 28th September, 2011

Kombo, K. \& Tromp, D. (2008). Proposal and Thesis Writing: An Introduction, p. 168. Nairobi: Pauline's Publications Africa (ISBN: 9966-08-106-2).

Kothari, R. (2008). Research methodology: Methods and Techniques, (pp. 1-56). New Delhi: New Age International (P) Limited, Publishers (ISBN 10:81224-1522-9).

Leavy, J. \& Hossain, N. (2014). Who Wants to Farm? Youth Aspirations, Opportunities and Rising Food Prices. IDS Working Papers, 2014(439), 1-44.

MoA (Ministry of Agriculture). (2013). Kajiado North District Strategic Plan. Implementation of the National Population Policy for Sustainable Development. National Coordinating Agency for Population and Development (2012-2017).

Njeru, L. Gichimu, B. Lopokoiyit, M. \& Mwangi J G. (2015). Influence of Kenyan Youth's Perception towards Agriculture and Necessary Interventions; a Review. Asian Journal of Agricultural Extension, Economics \& Sociology; 5(1): 40-45.

Noorani, M. (2015). To Farm or not to Farm? Rural Youth Perceptions of Farming and their Decision of Whether or not to Work as a Farmer. A Case Study of Rural Youth in Kiambu County, Kenya.

OECD (Organization for Economic Cooperation and Development). (2012). Organization for Economic Cooperation and Development). 2012. African Economic Outlook 2012. Paris. 
Paisley, C. (2012). Skill Gaps in Formal Higher Agricultural Education: A Youth Perspective. Background Paper for the Future Agriculture Conference on Young People, Farming and Food: The Future of the Agri Food Sector in Africa.

Proctor, F. \& Lucchesi, V. (2012). Small-scale farming and youth in an era of rapid rural Change. Retrieved September 24, 2013, from pubs.iied.org pdfs 14617II D.pdf 27

UNBS (Uganda National Bureau of Statistics). (2012). the National Labour Force and Child Activities.

UNDP (United Nations Development Program). (2013). Human Development Report 2013. New York. Survey 2011/12: Youth Employment Report.

UNESCO (United Nations Educational, Scientific and Cultural Organization). (2012). Reaching out-of-
School Children is Crucial for Development. UIS Factsheet, June 2012, No. 18.

UNICEF (United Nations International Children Education Fund). (2013). Education and

Gender Equality in Eastern and Southern Africa; 2010. Retrieved on $8^{\text {th }}$ august 2014 from http://www.unicef.org

World Bank. (2014). Agriculture Overview. Retrieved October 1, 2014, from http://www.worldbank.org/en/topic/agriculture/overvi ew\#1

World Bank. (2015). Unemployment Youth Totals (\% of Total Labour Force Ages 15-24). Retrieved May 2, 2015 from data.worldbank.org; indicators.

Cite this Article: Njeru LK (2017). Youth in Agriculture; Perceptions and Challenges for Enhanced Participation in Kajiado North Sub-County, Kenya. Greener Journal of Agricultural Sciences, 7(8): 203-209, http://doi.org/10.15580/GJAS.2017.8.100117141. 